\title{
Evaluation of the epidermal growth factor receptor gene mutation and copy number in non-small cell lung cancer with gefitinib therapy
}

\author{
KATSUHIKO ENDO, HIDEFUMI SASAKI, MOTOKI YANO, YOSHIHIRO KOBAYASHI, HARUHIRO YUKIUE, \\ HIROSHI HANEDA, ERIKO SUZUKI, OSAMU KAWANO and YOSHITAKA FUJII
}

Department of Surgery II, Nagoya City University Medical School, 1 Kawasumi, Mizuho-cho, Mizuho-ku, Nagoya 467-8601, Japan

Received February 23, 2006; Accepted May 16, 2006

\begin{abstract}
Several studies have suggested that epidermal growth factor receptor (EGFR) gene mutation, EGFR gene amplification, and some other biomarkers may be predictors of gefitinib sensitivity. We analyzed EGFR mutation and EGFR copy number in 22 gefitinib-treated non-small cell lung cancer (NSCLC) cases and their relation to the survival of patients. We also studied 143 gefitinib-naïve Japanese NSCLC cases. The ErbB2 copy number was also studied in 59 gefitinib-naïve NSCLC cases. In gefitinib-treated patients, the presence of EGFR mutation was associated with a higher response rate to gefitinib and a longer overall survival, but the increased EGFR gene copy number was not. In gefitinibnaïve cases, EGFR mutation but not EGFR gene copy number was significantly correlated with gender, pathological subtypes, and smoking status. The ErbB2 copy number was not significantly correlated with the EGFR mutation or EGFR copy number in 59 cases. In conclusion, EGFR mutation was a better predictor of clinical outcome in gefitinib-treated patients than the EGFR gene copy number.
\end{abstract}

\section{Introduction}

Lung cancer has a high mortality rate in many developed countries. Gefitinib inhibits tyrosine kinase (TK) activity of EGFR by reversibly competing with ATP at the ATP-binding cleft within the EGFR protein. Good clinical responses have been observed most frequently in women, in nonsmokers, in patients with adenocarcinomas, and in Japanese patients (1-4). Unfortunately, the addition of gefitinib to traditional chemotherapy did not add any benefit to patient survival for

Correspondence to: Dr Hidefumi Sasaki, Department of Surgery II, Nagoya City University Medical School, 1 Kawasumi, Mizuho-cho, Mizuho-ku, Nagoya 467-8601, Japan

E-mail: hisasaki@med.nagoya-cu.ac.jp

Key words: epidermal growth factor receptor mutation, epidermal growth factor receptor copy number, non-small cell lung cancer, gefitinib advanced NSCLC (3), although overexpression of EGFR protein was seen in relatively high frequencies (5). We and others have shown that the somatic mutation in the TK domain of the EGFR is associated with the sensitivity of NSCLC to gefitinib (6-8). The most frequently reported EGFR mutations are either deletion or single amino acid substitutions in exon 18, 19, or 21 clustered around the ATPbinding pocket of the TK domain. In vitro, EGFR mutation has been reported to confer enhanced TK activity in response to the epidermal growth factor (EGF) and increased sensitivity to the inhibition by gefitinib $(6,7,9,10)$. Thus, it is highly likely that EGFR mutation is a critical determinant of the patient's response to gefitinib.

Other biomarkers of NSCLC have also been studied. Some studies reported that downstream signaling molecules (particularly, the Akt signaling pathway), EGFR gene amplification, and the expression of the other ErbB receptors were the other predictors of gefitinib sensitivity. The EGFR and chromosome 7 copy numbers in NSCLC were assessed using fluorescence in situ hybridization (FISH), and more than 3 EGFR copies per cell (balanced polysomy or gene amplification) were detected in $39(22 \%)$ of 183 patients (11). A correlation between an increased EGFR copy number and gefitinib sensitivity was also proposed in another study from USA (12). Determining the EGFR gene mutation status and EGFR gene amplification may bring important information whether gefitinib is a therapeutic option for Japanese NSCLC patients. Therefore, we evaluated EGFR mutation and copy number as predictors of gefitinib sensitivity in patients with NSCLC in this study.

\section{Patients and methods}

Patients and genomic DNA. NSCLC tissues were obtained at Nagoya City University Hospital by surgical excision from 22 patients who were subsequently treated with gefitinib (Iressa ${ }^{\circledR}$, Astra Zeneca, London, UK) for their recurrent disease. The EGFR mutation and EGFR copy number were analyzed in these 22 gefitinib-treated samples. We also analyzed 143 additional gefitinib-naïve NSCLC cases operated between 1997 and 2000 at Nagoya City University Hospital. We evaluated the ErbB2 copy number in 59 of the additional 143 gefitinib-naïve NSCLC cases. The research 
was approved by the Institutional Review Board of the hospital. All the patients consented to the use of their tissues for the present analysis. The tissues were placed in liquid nitrogen immediately after resection or were formalin-fixed and paraffin-embedded. Genomic DNA was extracted using the Wizard SV Genomic DNA purification system (Promega) according to the manufacturer's instructions.

Analysis of EGFR mutation. Twenty-two gefitinib-treated samples and the additional 143 gefitinib-naïve NSCLC samples were analyzed by the TaqMan PCR assay (14) and direct sequencing (13). The primers and TaqMan ${ }^{\circledR}$ MGB probes were designed with Primer Express 2.0 software (Applied Biosystems). We designed 13 sets of specific TaqMan probes (14). TaqMan PCR and genotyping analysis were performed on 7500 Real Time PCR system (Applied Biosystems) according to the manufacturer's instructions.

Analysis of EGFR and ErbB2 copy number. EGFR copy number was analyzed for the 22 gefitinib-treated patients and for the additional 143 gefitinib-naïve NSCLC patients by quantitative real-time PCR, performed on 7500 Real Time PCR System using a QuantiTect SYBR-Green kit (Qiagen, Inc., Valencia, CA) as previously described (14). The ErbB2 copy number was also analyzed for the 59 gefitinib-naïve NSCLC patients by quantitative real-time PCR. An increased EGFR and an ErbB2 copy number was defined as more than three copies.

Clinical evaluation of the response to gefitinib. Tumor size was determined by computed tomographic (CT) scan of the chest before treatment. Tumor response was assessed by a CT scan 4 weeks after treatment. A complete response (CR) was defined as the disappearance of all clinical and radiological evidence of tumor for $>4$ weeks. A partial response (PR) required a $>50 \%$ reduction in the sum of the products of the perpendicular diameters of all measurable lesions for at least 4 weeks. Progressive disease (PD) was defined as the appearance of an unequivocal new lesion or an increase of $>25 \%$ in the sum of the products of the perpendicular diameters of any measured lesions. No change (NC) or stable disease was a change insufficient for PR or PD for at least 4 weeks after the start of therapy (15). Responders were defined as patients with CR or PR, and non-responders were defined as those with NC or PD. As patients with recurrent lung cancer often do not have measurable disease, we also included a change in the serum carcinoembryonic antigen (CEA) level (cut-off, $5 \mathrm{ng} / \mathrm{ml}$ ) as an evaluation criterion to avoid underestimating the effectiveness of gefitinib. When the elevated CEA decreased to a level less than half of the baseline level or within normal limit, gefitinib treatment was judged as effective or as partial response (PR) (16). Overall survival (OS) was calculated as the time from the start of gefitinib administration to death from any cause or last contact.

Statistical analysis. For comparison of proportions, the Fisher's Exact test was used. The overall survival was examined by the Kaplan-Meier method, and differences were examined by the log-rank test. The association of risk factors
Table I. Relationship between the EGFR copy number and clinicopathological factors in 22 gefitinib-treated patients.

\begin{tabular}{|c|c|c|c|}
\hline \multirow[b]{2}{*}{ Factors } & \multicolumn{2}{|c|}{ EGFR gene } & \multirow[b]{2}{*}{ P-value } \\
\hline & $\begin{array}{c}\text { Copy } \\
\text { number } \geq 3\end{array}$ & $\begin{array}{c}\text { Copy } \\
\text { number }<3\end{array}$ & \\
\hline \multicolumn{4}{|l|}{ Gender } \\
\hline Male & $4(30.8 \%)$ & 9 & 0.1150 \\
\hline Female & $0(0 \%)$ & 9 & \\
\hline \multicolumn{4}{|l|}{ Age } \\
\hline$\leq 64$ & $2(20 \%)$ & 8 & $>0.9999$ \\
\hline$>64$ & $2(16.7 \%)$ & 10 & \\
\hline \multicolumn{4}{|l|}{ Smoking status } \\
\hline Never-smokers & $0(0 \%)$ & 4 & 0.5055 \\
\hline Ever-smokers & $3(30 \%)$ & 7 & \\
\hline \multicolumn{4}{|l|}{ Differentiation } \\
\hline Well & $2(13.3 \%)$ & 13 & $>0.9999$ \\
\hline $\begin{array}{l}\text { Moderately or } \\
\text { poorly }\end{array}$ & $1(16.7 \%)$ & 5 & \\
\hline \multicolumn{4}{|l|}{ Pathological subtypes } \\
\hline Adeno & $4(22.2 \%)$ & 14 & 0.5538 \\
\hline Non-adeno & $0(0 \%)$ & 4 & \\
\hline
\end{tabular}

Adeno, adenocarcinoma.

associated with survival was evaluated using the Cox proportional hazards regression model. Only those variables with significant results in univariate analysis were included in the multivariate analysis. The analyses were done using a Stat View (version 5, SAS Institute Inc., Cary, NC) software and considered significant at p-value $<0.05$.

\section{Results}

EGFR mutation status in 22 gefitinib-treated patients. Using direct sequencing or the TaqMan PCR assay, 11 cases (50\%) were detected with an EGFR mutation. Four patients had deletion in exon 19, 5 patients had L858R mutation, one patient had G719S mutation, and one patient had a novel insertion in exon 20 (2316-2317 insertion GGT, P772_H773 ins V). The relationship between EGFR mutation and clinicopathological factors in 22 gefitinib-treated patients was evaluated. EGFR mutation was found in 5/13 (38.5\%) of males and $6 / 9(66.7 \%)$ of females; $6 / 10(60 \%)$ of patients who were $\leq 64$ years old and $5 / 12(41.7 \%)$ of patients who were $>64$ years old; $11 / 18(61.1 \%)$ of adenocarcinoma and $0 / 4(0 \%)$ of non-adenocarcinoma; $3 / 4(75 \%)$ of neversmokers and 2/10 (20\%) of ever-smokers; 9/15 (60\%) of welldifferentiated and $2 / 6(33.3 \%)$ of moderately or poorly differentiated NSCLC. None of the trends shown above reached statistical significance probably due to small sample size.

EGFR copy number in 22 gefitinib-treated patients. The EGFR copy number of 22 samples from patients who were 
Table II. Relationships among EGFR mutation, the EGFR copy number and gefitinib sensitivity.

\begin{tabular}{|c|c|c|c|c|c|c|}
\hline \multirow[b]{2}{*}{ EGFR gene } & \multicolumn{2}{|c|}{ Responders } & \multicolumn{2}{|c|}{ Non-responders } & \multirow[b]{2}{*}{$\begin{array}{l}\text { Responders/ } \\
\text { total patients }\end{array}$} & \multirow[b]{2}{*}{$\begin{array}{l}\text { Response } \\
\text { rates }(\%)\end{array}$} \\
\hline & $\mathrm{CR}$ & PR & $\mathrm{NC}$ & PD & & \\
\hline Mutant & 0 & 9 & 1 & 1 & $9 / 11$ & $81.8^{\mathrm{a}}$ \\
\hline Wild-type & 0 & 2 & 4 & 5 & $2 / 11$ & $18.2^{\mathrm{a}}$ \\
\hline Copy number $\geq 3$ & 0 & 1 & 0 & 3 & $1 / 4$ & $25^{b}$ \\
\hline Copy number <3 & 0 & 10 & 5 & 3 & $10 / 18$ & $55.6^{\mathrm{b}}$ \\
\hline Total & 0 & 11 & 5 & 6 & $11 / 22$ & 50 \\
\hline
\end{tabular}

${ }^{\mathrm{a}} \mathrm{p}=0.0089 ;{ }^{\mathrm{b}} \mathrm{p}=0.5865$ (Fisher's exact test); CR, complete response; PR, partial response; NC, no change; PD, progressive disease.

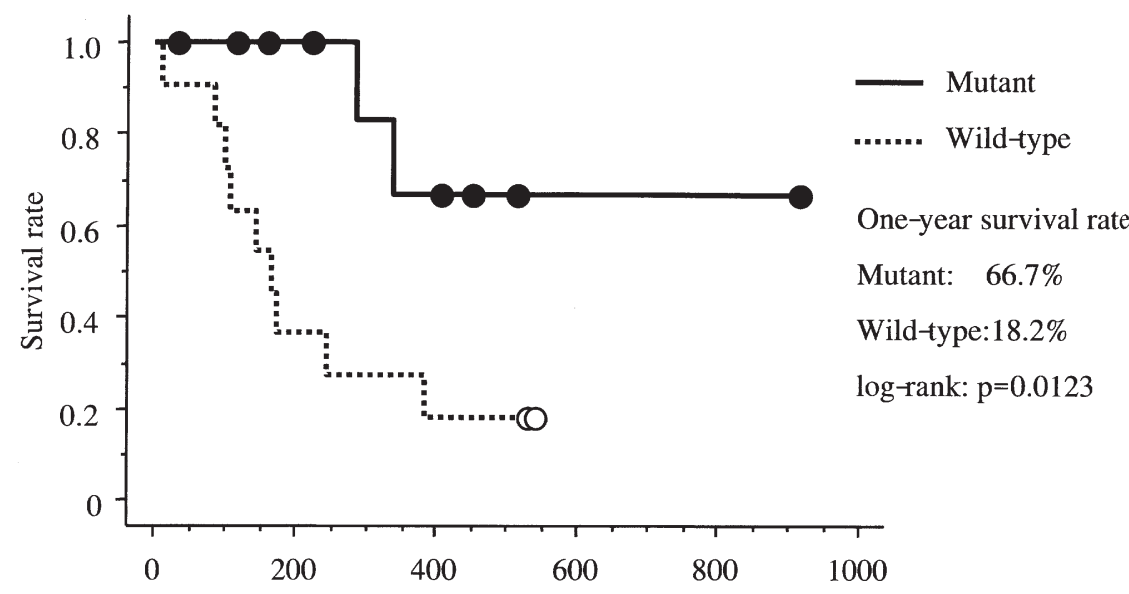

Days from the start of gefitinib administration

Figure 1. Kaplan-Meier curves of overall survival according to EGFR mutation in 22 gefitinib-treated patients. One-year survival rate of the patients with EGFR mutation was $66.7 \%$ vs $18.2 \%$ of the patients with wild-type EGFR. Patients with EGFR mutation had a statistically significantly longer OS compared with those with wild-type EGFR (log-rank $\mathrm{p}=0.0123$ ).

treated with gefitinib was analyzed by quantitative real-time PCR. Four of 22 cases were found to have an increased EGFR copy number. Relationship between EGFR copy number and clinicopathological factors in 22 gefitinib-treated patients is shown in Table I. An increased EGFR copy number was found in $4 / 13(30.8 \%)$ of males and $0 / 9(0.0 \%)$ of females; $2 / 10(20 \%)$ of patients who were $\leq 64$ years old and $2 / 12(16.7 \%)$ of those who were $>64$ years old; $4 / 18$ (22.2\%) of adenocarcinoma and $0 / 4$ (0\%) of nonadenocarcinoma; 0/4 (0\%) of never-smokers and 3/10 (30\%) of ever-smokers; $2 / 15$ (13.3\%) of well-differentiated and 1/6 (16.7\%) of moderately or poorly differentiated NSCLC. The EGFR copy number was not significantly correlated with any of clinicopathological factors. In the 11 cases with EGFR mutation in this cohort, only one case had an increased EGFR copy number. The EGFR copy number did not correlate with the EGFR mutation status $(\mathrm{p}=0.5865)$.

Gefitinib sensitivity in 22 gefitinib-treated patients. Relationship between gefitinib sensitivity and clinicopathological factors in 22 gefitinib-treated patients was evaluated. Responders (CR or PR) to gefitinib were 5/13 $(38.5 \%)$ of males and $6 / 9(66.7 \%)$ of females; $5 / 10(50 \%)$ of patients who were $\leq 64$ years old and $6 / 12(50 \%)$ of those who were $>64$ years old; $10 / 18(55.6 \%)$ of adenocarcinoma and $1 / 4(25 \%)$ of non-adenocarcinoma; $3 / 4(75 \%)$ of neversmokers and 3/10 (30\%) of ever-smokers; 9/15 (60\%) of well-differentiated and 2/6 (33.3\%) of moderately or poorly differentiated NSCLC. There was no significant correlation between the response to gefitinib and these clinicopathological factors.

Relationships among EGFR mutation, the EGFR copy number, gefitinib sensitivity and clinical outcome. Relationships among EGFR mutation, the EGFR copy number and gefitinib sensitivity are shown in Table II. The response rates of patients with mutant and wild-type EGFR were $81.8 \%$ and $18.2 \%$, respectively $(\mathrm{p}=0.0089)$. Two patients with EGFR mutation were non-responders; one patient was judged as NC and one patient had PD. The patient with PD had a novel exon 20 insertion (P772_H773 insV). The Kaplan-Meier curves of OS according to EGFR mutation in 


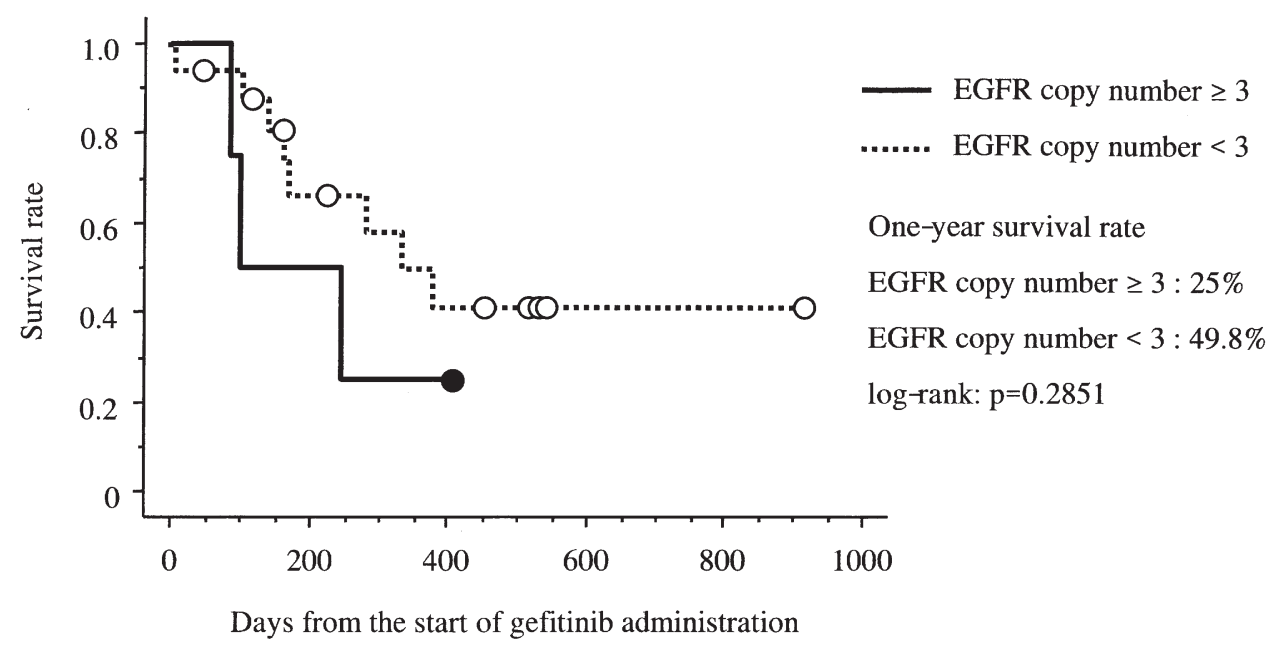

Figure 2. Kaplan-Meier curves of overall survival according to the EGFR copy number in 22 gefitinib-treated patients. One-year survival rate of the patients with an increased EGFR copy number was $25 \%$ vs $49.8 \%$ of the patients without an increased EGFR copy number. The difference did not reach statistical significance $(\log -$ rank $\mathrm{p}=0.2851)$.

Table III. Univariate and multivariate analyses of association between clinicopathological factors and overall survival in patients with gefitinib therapy.

\begin{tabular}{lcc}
\hline & Univariate & Multivariate \\
\cline { 2 - 3 } Risk factors & P-value & P-value \\
\hline Gender (male vs female) & 0.0084 & 0.5949 \\
Age ( $\leq 64$ years vs $>64$ years) & 0.9135 & - \\
Pathological sybtypes (adeno vs non-adeno) & 0.0124 & 0.3525 \\
Smoking status (never-smokers vs ever-smokers) & 0.0094 & 0.6570 \\
Differentiation (well vs moderately or poorly) & 0.0250 & 0.9748 \\
EGFR mutation (mutant vs wild-type) & 0.0123 & 0.3680 \\
EGFR copy number (<3 vs $\geq 3$ ) & 0.2851 & - \\
Gefitinib response (responders vs non-responders) & 0.0453 & 0.1758 \\
\hline
\end{tabular}

Adeno, adenocarcinoma.

22 gefitinib-treated patients are shown in Fig. 1. One-year survival rate of the patients with EGFR mutation was $66.7 \%$ vs $18.2 \%$ of the patients with wild-type EGFR. Patients with EGFR mutation had a statistically significantly longer OS compared with those with wild-type EGFR (log-rank $\mathrm{p}=0.0123$ ). The response rates of patients with an increased EGFR copy number (EGFR copy number $\geq 3$ ) and without an increased EGFR copy number (EGFR copy number $<3$ ) were $25 \%$ and $55.6 \%$, respectively $(\mathrm{p}=0.5865)$. Three patients with an increased EGFR copy number were non-responders; all three patients had PD. The Kaplan-Meier curves of OS according to EGFR copy number in 22 gefitinib-treated patients are shown in Fig. 2. One-year survival rate of the patients with an increased EGFR copy number was $25 \%$ vs $49.8 \%$ of the patients without an increased EGFR copy number. However, the difference did not reach statistical significance $(\log$-rank $\mathrm{p}=0.2851)$. The presence of EGFR mutation was significantly associated with a higher response rate and a longer OS. However, the association of an increased EGFR copy number and lower response rate or a shorter OS was not statistically significant, possibly due to the small number of patients with an increased EGFR copy number. To define which variables were predictive for survival, those factors that were statistically significant in the univariate analysis were included in the multivariate analysis. Univariate and multivariate analyses of association between clinicopathological factors and overall survival in patients with gefitinib therapy are shown in Table III. In the univariate analyses, OS was significantly associated with gender (male vs female, $\mathrm{p}=0.0084$ ), pathological subtypes (adenocarcinoma vs non-adenocarcinoma, $\mathrm{p}=0.0124$ ), smoking status (never-smokers vs ever-smokers, $\mathrm{p}=0.0094$ ), differentiation (well differentiated vs moderately or poorly differentiated, $\mathrm{p}=0.0250$ ), EGFR mutation (mutant vs wild- 
Table IV. Relationship between EGFR mutation and clinicopathological factors in the additional 143 gefitinib-naïve NSCLC patients.

\begin{tabular}{|c|c|c|c|}
\hline \multirow[b]{2}{*}{ Factors } & \multicolumn{2}{|c|}{ EGFR gene } & \multirow[b]{2}{*}{ P-value } \\
\hline & Mutant & Wild-type & \\
\hline \multicolumn{4}{|l|}{ Gender } \\
\hline Male & $12(11 \%)$ & 97 & $<0.0001$ \\
\hline Female & $19(55.9 \%)$ & 15 & \\
\hline \multicolumn{4}{|l|}{ Age } \\
\hline$\leq 64$ & $16(24.6 \%)$ & 49 & 0.5416 \\
\hline$>64$ & $15(19.2 \%)$ & 63 & \\
\hline \multicolumn{4}{|l|}{ Smoking status } \\
\hline Never-smokers & $17(48.6 \%)$ & 18 & $<0.0001$ \\
\hline Ever-smokers & $12(12.4 \%)$ & 83 & \\
\hline \multicolumn{4}{|c|}{ Lymph node metastasis } \\
\hline N0 & $21(23.3 \%)$ & 69 & 0.6749 \\
\hline $\mathrm{N}+$ & $10(18.9 \%)$ & 43 & \\
\hline \multicolumn{4}{|l|}{ Differentiation } \\
\hline Well & $18(29 \%)$ & 44 & 0.1020 \\
\hline $\begin{array}{l}\text { Moderately or } \\
\text { poorly }\end{array}$ & $12(16.9 \%)$ & 59 & \\
\hline \multicolumn{4}{|c|}{ Pathological subtypes } \\
\hline Adeno & $27(31 \%)$ & 60 & 0.0007 \\
\hline Non-adeno & $4(7.1 \%)$ & 52 & \\
\hline \multicolumn{4}{|l|}{ pStage } \\
\hline I & $17(27 \%)$ & 46 & 0.2230 \\
\hline II-IV & $14(17.5 \%)$ & 66 & \\
\hline
\end{tabular}

$\mathrm{N}+$, lymph node metastasis-positive; adeno, adenocarcinoma.

type, $\mathrm{p}=0.0123$ ), and gefitinib response (responders vs nonresponders, $\mathrm{p}=0.0453$ ), but not the EGFR copy number $(p=0.2851)$. However, in the multivariate analyses, none of these was a significant prognostic factor, including the EGFR mutation $(\mathrm{p}=0.3680)$.

EGFR mutation status in the additional 143 gefitinib-naïve NCSLC patients. EGFR mutation was analyzed for the additional 143 gefitinib-naïve NSCLC patients who were not treated by gefitinib using direct sequencing or the TaqMan PCR assay. Thirty-one mutations were detected; 18 patients had the deletion in exon 19,11 patients had L858R mutation, one patient had G719S mutation, and one patient had a novel insertion mutation in exon 20 (P772_H773 ins V). The relationship between EGFR mutation and clinicopathological factors in the additional 143 gefitinib-naïve patients is shown in Table IV. EGFR mutation status was significantly correlated with gender (male vs female, $\mathrm{p}<0.0001$ ), pathological subtypes (adenocarcinoma vs non-adenocarcinoma,
Table V. Relationship between the EGFR copy number and clinicopathological factors in the additional 143 gefitinibnaïve NSCLC patients.

\begin{tabular}{|c|c|c|c|}
\hline \multirow[b]{2}{*}{ Factors } & \multicolumn{2}{|c|}{ EGFR gene } & \multirow[b]{2}{*}{ P-value } \\
\hline & $\begin{array}{c}\text { Copy } \\
\text { number } \geq 3\end{array}$ & $\begin{array}{c}\text { Copy } \\
\text { number }<3\end{array}$ & \\
\hline \multicolumn{4}{|l|}{ Gender } \\
\hline Male & $9(8.2 \%)$ & 100 & 0.4519 \\
\hline Female & $1(2.9 \%)$ & 33 & \\
\hline \multicolumn{4}{|l|}{ Age } \\
\hline$\leq 64$ & $8(12.3 \%)$ & 57 & 0.0433 \\
\hline$>64$ & $2(2.6 \%)$ & 76 & \\
\hline \multicolumn{4}{|l|}{ Smoking status } \\
\hline Never-smokers & $3(8.6 \%)$ & 32 & 0.7014 \\
\hline Ever-smokers & $6(6.3 \%)$ & 89 & \\
\hline \multicolumn{4}{|c|}{ Lymph node metastasis } \\
\hline No & $8(8.9 \%)$ & 82 & 0.3230 \\
\hline $\mathrm{N}+$ & $2(3.8 \%)$ & 51 & \\
\hline \multicolumn{4}{|l|}{ Differentiation } \\
\hline Well & $3(4.8 \%)$ & 59 & 0.3365 \\
\hline $\begin{array}{l}\text { Moderately or } \\
\text { poorly }\end{array}$ & $7(9.9 \%)$ & 64 & \\
\hline \multicolumn{4}{|l|}{ Pathological subtypes } \\
\hline Adeno & $4(4.6 \%)$ & 83 & 0.1899 \\
\hline Non-adeno & $6(10.7 \%)$ & 50 & \\
\hline \multicolumn{4}{|l|}{ pStage } \\
\hline I & $5(7.9 \%)$ & 58 & 0.7494 \\
\hline II-IV & $5(6.3 \%)$ & 75 & \\
\hline
\end{tabular}

$\mathrm{N}+$, lymph node metastasis-positive; adeno, adenocarcinoma.

$\mathrm{p}=0.0007$ ), and smoking status (never-smokers vs eversmokers, $\mathrm{p}<0.0001)$. Patients with EGFR mutation did not have a statistically significantly longer OS compared with those with wild-type EGFR (log-rank $\mathrm{p}=0.9787$, data not shown).

EGFR copy number in the additional 143 gefitinib-naïve NCSLC patients. The EGFR copy number was analyzed for the additional 143 gefitinib-naïve NSCLC patients by quantitative real-time PCR. Ten of the 143 cases (7.0\%) were found to have an increased EGFR copy number. The relationship between the EGFR copy number and clinicopathological factors in the additional 143 gefitinib-naïve NSCLC patients is shown in Table V. An increased EGFR copy number was found in $9 / 109(8.2 \%)$ of males and $1 / 34$ $(2.9 \%)$ of females; $8 / 65(12.3 \%)$ of those who were $\leq 64$ years old and $2 / 78(2.6 \%)$ of those who were $>64$ years old; $4 / 87(4.6 \%)$ of adenocarcinoma and $6 / 56(10.7 \%)$ of non- 


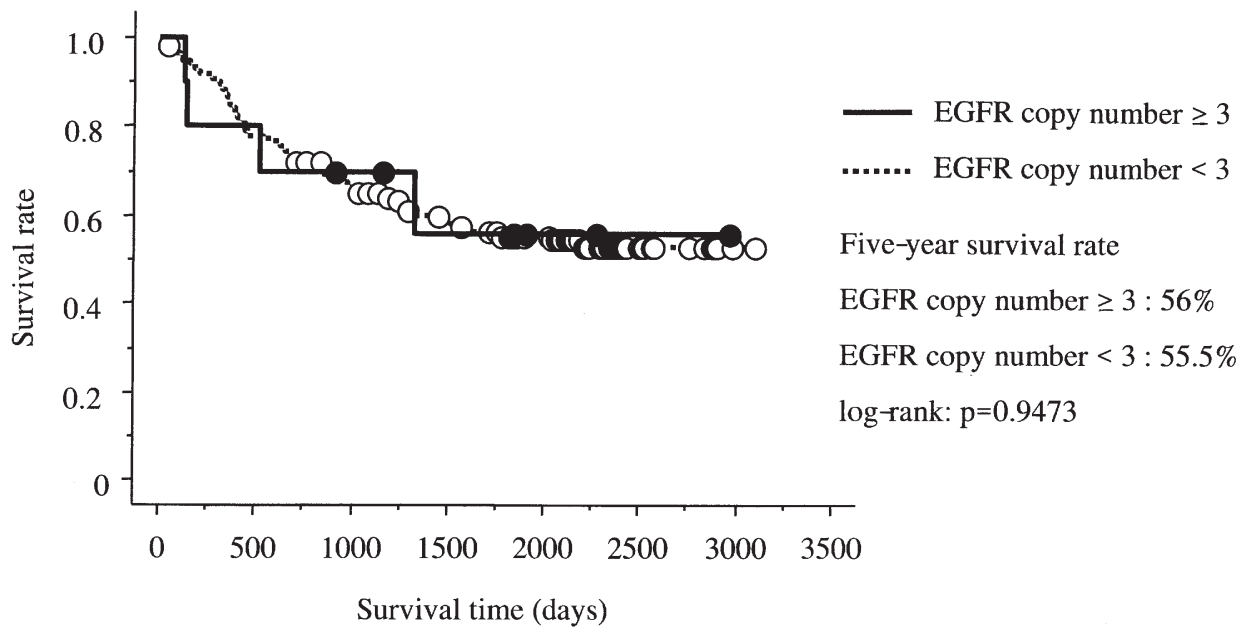

Figure 3. Kaplan-Meier curves of overall survival according to the EGFR copy number in the additional 143 gefitinib-naïve NSCLC patients. Survival time was calculated as the time from operation to death from any cause or last contact. Five-year survival rate of the patients with an increased EGFR copy number was $56 \%$ vs $55.5 \%$ of the patients without an increased EGFR copy number. The difference did not reach statistical significance (log-rank p=0.9473).

Table VI. Relationship between the ErbB2 copy number and clinicopathological factors in 59 gefitinib-naïve NSCLC patients.

\begin{tabular}{lcc}
\hline & \multicolumn{2}{c}{ ErbB2 gene } \\
\cline { 2 - 3 } Factors & $\begin{array}{c}\text { Copy } \quad \text { Copy } \\
\text { number } \geq 3\end{array}$ & Pumber $<3$
\end{tabular}

\begin{tabular}{llll}
\hline $\begin{array}{l}\text { Gender } \\
\text { Male }\end{array}$ & $7(16.3 \%)$ & 36 & $>0.9999$ \\
$\quad$ Female & $2(12.5 \%)$ & 14 & \\
Age & & & \\
$\quad \leq 64$ & $5(17.9 \%)$ & 23 & 0.7231 \\
$\quad>64$ & $4(12.9 \%)$ & 27 & \\
Smoking status & & & \\
$\quad$ Never-smokers & $2(11.1 \%)$ & 16 & 0.7080 \\
$\quad$ Ever-smokers & $7(17.1 \%)$ & 34 & \\
Differentiation & & & \\
$\quad$ Well & $4(13.3 \%)$ & 26 & 0.7220 \\
$\quad$ Moderately or & $5(18.5 \%)$ & 22 & \\
$\quad$ poorly & & & \\
Pathological subtypes & & & \\
$\quad$ Adeno & $8(20.0 \%)$ & 32 & 0.2473 \\
$\quad$ Non-adeno & $1(5.3 \%)$ & 18 & \\
\hline
\end{tabular}

Adeno, adenocarcinoma.

adenocarcinoma; $3 / 35(8.6 \%)$ of never-smokers and 6/95 $(6.3 \%)$ of ever-smokers; $8 / 90(8.9 \%)$ of those with no lymph node metastasis and $2 / 53(3.8 \%)$ of those with lymph node metastasis; $3 / 62(4.8 \%)$ of well differentiated and 7/71
(9.9\%) of moderately or poorly differentiated NSCLC; 5/63 (7.9\%) of pStage I and 5/80 (6.3\%) of pStage II-IV patients. The EGFR copy number was significantly correlated with age ( $\leq 64$ years vs $>64$ years, $p=0.0433$ ), but not with any other clinicopathologic factor. In the 31 cases with EGFR mutation in this cohort, only two cases had an increased EGFR copy number. The EGFR copy number did not correlate with EGFR mutation status ( $p>0.9999)$. The Kaplan-Meier curves of OS according to EGFR copy number in the additional 143 gefitinib-naïve NSCLC patients are shown in Fig. 3. The five-year survival rate of the patients with an increased EGFR copy number was $56 \%$ vs $55.5 \%$ of the patients without an increased EGFR copy number. The difference did not reach statistical significance (log-rank $\mathrm{p}=0.9473$ ).

ErbB2 copy number in 59 gefitinib-naïve NCSLC patients. In the 59 gefitinib-naïve NSCLC samples, ErbB2 copy number was analyzed. The relationship between the ErbB2 copy number and the clinicopathologic factors in the 59 gefitinibnaïve NSCLC patients is shown in Table VI. An increased ErbB2 copy number was found in $7 / 43(16.3 \%)$ of males and $2 / 16(12.5 \%)$ of females; $5 / 28(17.9 \%)$ of those who were $\leq 64$ years old and $4 / 31(12.9 \%)$ of those who were $>64$ years old; 8/40 (20\%) of adenocarcinoma and 1/19 (5.3\%) of nonadenocarcinoma; $2 / 18(11.1 \%)$ of never-smokers and 7/41 $(17.1 \%)$ of ever-smokers; $4 / 30(13.3 \%)$ of well-differentiated and $5 / 27(18.5 \%)$ of moderately or poorly differentiated NSCLC. The ErbB2 copy number was not significantly correlated with any of clinicopathological factors. The Kaplan-Meier curves of OS according to ErbB2 copy number in the 59 gefitinib-naïve NSCLC patients are shown in Fig. 4. The five-year survival rate of the patients with an increased ErbB2 copy number was $63.5 \%$ vs $55.1 \%$ of the patients without an increased ErbB2 copy number. The difference did not reach statistical significance $(\log$-rank $\mathrm{p}=0.4133)$.

Relationships among EGFR copy number, the ErbB2 copy number and EGFR mutation. In the 59 gefitinib-naïve 


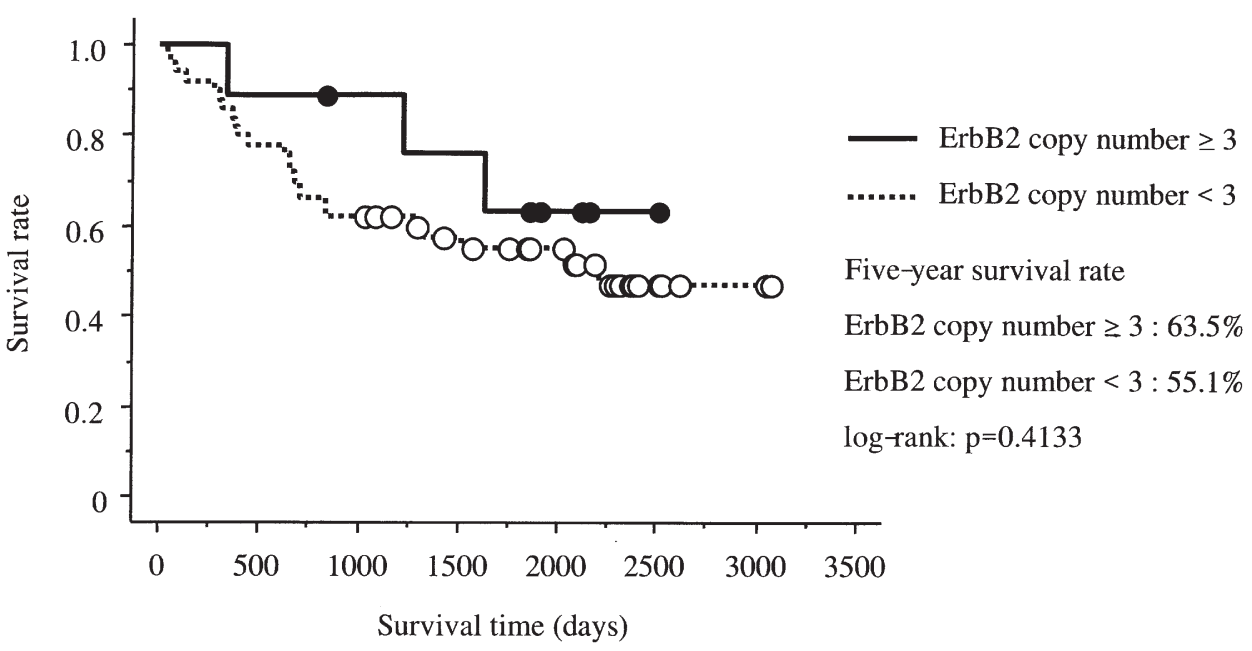

Figure 4. Kaplan-Meier curves of overall survival according to the ErbB2 copy number in 59 gefitinib-naïve NSCLC patients. Survival time was calculated as the time from operation to death from any cause or last contact. Five-year survival rate of the patients with an increased ErbB2 copy number was $63.5 \%$ vs $55.1 \%$ of the patients without an increased ErbB2 copy number. The difference did not reach statistical significance (log-rank $\mathrm{p}=0.4133)$.

NSCLC patients, 16 EGFR mutations were detected. Five of the 59 cases were found to have an increased EGFR copy number and nine of 59 cases were found to have an increased ErbB2 copy number. Only one patient had both an increased ErbB2 copy number and an EGFR mutation. Only one patient had both increased ErbB2 copy number and increased EGFR copy number. The ErbB2 copy number was not significantly correlated with the EGFR mutation $(\mathrm{p}=0.4206)$ or the EGFR copy number $(\mathrm{p}=0.5768)$.

\section{Discussion}

In our study, EGFR mutation, but not the EGFR copy number, correlated with survival of patients treated with gefitinib. Gefitinib showed a promising effect on a few types of cancer in a phase I trial (1). Subsequently, however, in phase II randomized trials in which the drug was used in combination with traditional chemotherapy, the effect was marginal in patients with NSCLC (7). Our group and others have reported on identification of genetic mutations in the EGFR kinase domain $(6,7)$. EGFR mutation was seen in a subset of NSCLC with a good response to gefitinib. These reports triggered further studies on EGFR mutation and the tumor's response to gefitinib and erlotinib (6-8). All the groups identified recurrent mutations in the same region around the ATP-binding pocket in the EGFR tyrosine kinase domain. In vitro studies have reported that the kinase activity of EGFR or the sensitivity to gefitinib showed a strong association with EGFR gene mutation $(7,9)$. In our analysis, the response rates of patients with mutant and wild-type EGFR were $81.8 \%$ and $18.2 \%$, respectively $(p=0.0089)$. The presence of EGFR mutation was significantly associated with a higher response rate. Nine of $11(81.8 \%)$ gefitinibresponders had an EGFR mutation and only two of the 11 (18.2\%) patients with wild-type EGFR were gefitinibresponders. The presence of two gefitinib-responding tumors with wild-type EGFR may be because i) the EGFR mutation analysis was not sensitive enough, ii) the EGFR mutation occurred in the tumors after the primary surgery (whose sample we analyzed) or iii) other factors of gefitinib sensitivity were present (17). There was a statistically significantly correlation between EGFR mutation and gefitinib sensitivity or overall survival in our analysis and from the analysis of the other groups $(16,18-20)$. Thus, these results demonstrated that EGFR mutation was a critical determinant of gefitinib sensitivity, at least in the Japanese population. One EGFRmutant patient was resistant to gefitinib therapy. This patient had a novel insertion at exon 20 (P772_H773 ins V). Several recent reports show that exon 20 mutations, such as T790M and D770_N771 ins NPG, are correlated with gefitinib resistance $(21,22)$.

In this report, the response rates to gefitinib of patients with an increased EGFR copy number and without an increased EGFR copy number were $25 \%$ and $49.8 \%$, respectively $(\mathrm{p}=0.2851)$. One of $11(9.1 \%)$ of gefitinibresponders and $3 / 11(27.3 \%)$ of gefitinib non-responders had an increased EGFR copy number. Ten of 18 (55.6\%) patients without an increased EGFR copy number were gefitinibresponders. Some studies reported that an increased EGFR copy number was associated with gefitinib sensitivity. For example, Hirsch et al (11) reported that patients with an increased EGFR gene copy number had a trend for higher response rates and a longer time to progression after gefitinib therapy, and Cappuzzo et al (12) reported that a high EGFR gene copy number was associated with a better response and better survival. However, there was no statistically significant correlation between an increased EGFR copy number and gefitinib sensitivity or overall survival in our analysis and we were unable to show any differences in increased EGFR copy number between tumors carrying the wild-type EGFR sequence and tumors carrying the mutant EGFR sequence, which is not surprising as it has been convincingly shown that EGFR mutation and not the expression levels is responsible for the clinical response to EGFR tyrosine kinase inhibitors $(6,7,23)$. The difference between the previously published studies and ours might be caused by the difference in ethnicity; Caucasian or Oriental. Thus, whether an increased EGFR copy number is a 
predictor of gefitinib sensitivity, remains to be determined. The results of multivariate analyses suggested that none of clinicopathological factors, including EGFR mutation was an independent predictor of prognosis. Further studies will be needed to delineate the relationships among EGFR mutation, EGFR gene copy number, EGFR mRNA expression, gefitinib sensitivity, and prognosis.

In our analysis of the additional 143 gefitinib-naïve cases, EGFR mutation status was significantly correlated with gender, pathological subtypes, and smoking status. This result confirmed and extended the results of previous reports $(6,8,9,24)$. The EGFR copy number was significantly correlated with age only, and did not significantly affect the OS in the additional 143 gefitinib-naïve cases.

Overexpression of EGFR/ErbB2 and ErbB ligands was correlated with advanced disease and poor patient prognosis (25). The EGFR-ErbB2 heterodimers were associated with a stronger and more sustained proliferative signal than the EGFR homodimers $(26,27)$. HER2 mutations were in-frame insertions in exon 20 and were significantly more frequent in never smokers and adenocarcinoma histology (28). Thus, some studies have reported on ErbB2 gene expression and mutation, but very few studies have reported on the association between the ErbB2 gene copy number and lung cancer. Cappuzzo et al (29) reported that HER2 gene gain was significantly associated with EGFR gene gain and with EGFR gene mutations, and that EGFR-positive patients who also had increased copy numbers of the HER2 gene had a better response rate, disease control rate, TTP, and survival. Because analysis of the ErbB2 copy number was not performed in gefitinib-treated patients, we were not able to show the relationship between the ErbB2 gene copy number and gefitinib sensitivity. However, we have shown that the ErbB2 copy number was not significantly correlated with the EGFR mutation and EGFR copy number in the 59 gefitinibnaïve NSCLC cases.

In summary, EGFR mutation was significantly associated with a better clinical outcome in gefitinib-treated patients, but an increased EGFR gene copy number was not significantly associated with a better clinical outcome in gefitinib-treated patients and the additional 143 gefitinibnaïve NSCLC cases. The populations with EGFR mutation may be different from the populations with an increased EGFR copy number and the effect of an increased EGFR copy number to gefitinib response may be different from that of EGFR mutation. However, for another TK inhibitor erlotinib (Tarceva ${ }^{\circledR}$, Genetech), because the dose setting was different from gefitinib therapy, EGFR amplification may still be a better predictor of erlotinib sensitivity for lung cancers (30). In most studies, analysis of the EGFR copy number was performed by FISH or quantitative real-time PCR. FISH analysis was relatively expensive and was usually performed on one or few of the sliced sections. On the other hand, quantitative real-time PCR method is inexpensive, relatively easy, and efficient. Therefore, we adopted the latter method. Although the methods suited for the analysis of the EGFR copy number cannot be determined, standardization of the EGFR copy number analysis is required to evaluate the EGFR copy number accurately.
Further studies are required to evaluate the predictive values of some biomarkers other than EGFR mutation and the EGFR copy number, and future clinical trials may need to incorporate several predictive biomarkers in molecular targeted therapy including gefitinib and erlotinib.

\section{Acknowledgements}

The authors would like to thank Dr Xiaojun Zhao for his excellent technical assistance with DNA amplification assay, and Dr Naoya Hosono for the TaqMan PCR assay. This study was supported by a grant for cancer research from the Ministry of Education, Culture, Sports, Science and Technology of Japan and Astra Zeneca Research grant 2004.

\section{References}

1. Baselga J, Rischin D, Ranson M, et al : Phase I safety, pharmacokinetic, and pharmacodynamic trial of ZD1839, a selective oral epidermal growth factor receptor tyrosine kinase inhibitor, in patients with five selected solid tumor types. J Clin Oncol 20: 4292-4302, 2002.

2. Fukuoka M, Yano S, Giaccone G, et al: Multi-institutional randomized phase II trial of gefitinib for previously treated patients with advanced non-small-cell lung cancer. J Clin Oncol 21: 2237-2246, 2003.

3. Giaccone G, Herbst RS, Manegold C, et al: Gefitinib in combination with gemcitabine and cisplatin in advanced nonsmall-cell lung cancer: a phase III trial - INTACT 1. J Clin Oncol 22: 777-784, 2004.

4. Kris MG, Natale RB, Herbst RS, et al: Efficacy of gefitinib, an inhibitor of the epidermal growth factor receptor tyrosine kinase, in symptomatic patients with non-small cell lung cancer: a randomized trial. JAMA 290: 2149-2158, 2003.

5. Rusch V, Baselga J, Cordon-Cardo C, et al: Differential expression of the epidermal growth factor receptor and its ligands in primary non-small cell lung cancers and adjacent benign lung. Cancer Res 53: 2379-2385, 1993.

6. Lynch TJ, Bell DW, Sordella R, et al: Activating mutations in the epidermal growth factor receptor underlying responsiveness of non-small-cell lung cancer to gefitinib. N Engl J Med 350: 2129-2139, 2004.

7. Paez JG, Jänne PA, Lee JC, et al: EGFR mutations in lung cancer: correlation with clinical response to gefitinib therapy. Science 304: 1497-1500, 2004.

8. Pao W, Miller V, Zakowski M, et al: EGF receptor gene mutation are common in lung cancer from 'never smokers' and are associated with sensitivity of tumors to gefitinib and elrotinib. Proc Natl Acad Sci USA 101: 13306-13311, 2004.

9. Sordella R, Bell DW, Haber DA and Settleman J: Gefitinibsensitizing EGFR mutations in lung cancer activate antiapoptotic pathways. Science 305: 1163-1167, 2004.

10. Tracy S, Mukohara T, Hansen M, Meyerson M, Johnson BE and Jänne PA: Gefitinib induces apoptosis in the EGFR L858R non-small cell lung cancer cell line H3255. Cancer Res 64: 7241-7244, 2004.

11. Hirsch FR, Varella-Garcia M, Bunn PA Jr, et al: Epidermal growth factor receptor in non-small-cell lung carcinomas: correlation between gene copy number and protein expression and impact on prognosis. J Clin Oncol 21: 3798-3807, 2003.

12. Cappuzzo F, Hirsch FR, Rossi E, et al: Epidermal growth factor receptor gene and protein and gefitinib sensitivity in non-smallcell lung cancer. J Natl Cancer Inst 97: 643-655, 2005.

13. Sasaki H, Shimizu S, Endo K, et al: EGFR and ErbB2 mutation status in Japanese lung cancer patients. Int J Cancer 118: 180-184, 2006.

14. Endo K, Konishi A, Sasaki H, et al: Epidermal growth factor receptor gene mutation in non-small cell lung cancer using highly sensitive and fast TaqMan PCR assay. Lung Cancer 50: 375-384, 2005.

15. Kawahara M, Furuse K, Segawa Y, et al: Phase II study of S-1, a novel oral fluorouracil, in advanced non-small-cell lung cancer. Br J Cancer 85: 939-943, 2001. 
16. Mitsudomi T, Kosaka T, Endoh H, et al: Mutations of the epidermal growth factor gene predict prolonged survival after gefitinib treatment in patients with non-small-cell lung cancer with postoperative recurrence. J Clin Oncol 23: 2513-2520, 2005 .

17. Takano T, Ohe Y, Sakamoto H, et al: Epidermal growth factor receptor gene mutations and increased copy numbers predict gefitinib sensitivity in patients with recurrent non-small-cell lung cancer. J Clin Oncol 23: 6829-6837, 2005.

18. Han SW, Kim TY, Hwang PG, et al: Predictive and prognostic impact of epidermal growth factor receptor mutation in nonsmall cell lung cancer patients treated with gefitinib. J Clin Oncol 23: 2493-2501, 2005.

19. Kim KS, Jeong JY, Kim YC, et al: Predictors of the response to gefitinib in refractory non-small cell lung cancer. Clin Cancer Res 11: 2244-2251, 2005.

20. Taron M, Ichinose Y, Rosell R, et al: Activating mutations in the tyrosine kinase domain of the epidermal growth factor receptor are associated with improved survival in gefitinibtreated chemorefractory lung adenocarcinomas. Clin Cancer Res 11: 5878-5885, 2005.

21. Greulich H, Chen TH, Freg W, et al: Oncogenic transformation by inhibitor-sensitive and-resistant EGFR mutants. PLoS Med 2: e313 (Epub ahead of print), 2005.

22. Kobayashi S, Boggon TJ, Dayaram T, et al: EGFR mutation and resistance of non-small-cell lung cancer to gefitinib. N Engl J Med 352: 786-792, 2005.
23. Jänne PA, Gurubhagavatula S, Yeap BY, et al: Outcomes of patients with advanced non-small cell lung cancer treated with gefitinib (ZD1839, 'Iressa' on an expanded access study. Lung Cancer 44: 221-230, 2004.

24. Kosaka T, Yatabe Y, Endoh H, Kuwano H, Takahashi T and Mitsudomi T: Mutations of the epidermal growth factor receptor gene in lung cancer: biological and clinical implications. Cancer Res 64: 8919-8923, 2004

25. Pegram $M$ and Slamon D: Biological rationale for HER2/neu (c-erB2) as a target for monoclonal antibody therapy. Semin Oncol 5 (suppl 9): 13-19, 2000

26. Brabender J, Danenber KD, Metzger R, et al: Epidermal growth factor and HER2-neu mRNA expression in non-small cell lung cancer is correlated with survival. Clin Cancer Res 7: 1850-1855, 2001.

27. Yarden $Y$ and Sliwkowski MX: Untangling the erbB2 signaling network. Nat Rev Mol Cell Biol 2: 127-137, 2001.

28. Shigematsu H, Takahashi T, Nomura M, et al : Somatic mutations of HER2 kinase domain in lung adenocarciomas. Cancer Res 65: 1642-1646, 2005

29. Cappuzzo F, Garcia MV, Shigematsu H, et al: Increased HER2 gene copy number is associated with response to gefitinib therapy in epidermal growth factor-positive non-small-cell lung cancer patients. J Clin Oncol 23: 5007-5018, 2005.

30. Tsao MS, Sakurada A, Cutz JC, et al: Erlotinib in lung cancermolecular and clinical predictors of outcome. N Engl J Med 353: 133-144, 2005. 